\title{
Solar water heating systems for different buildings under a hot climate; parametric optimization and economic analysis
}

\author{
Kheira Tabet Aoul*, Ahmad Hasan, and Hassan Riaz \\ Architectural Engineering Department, College of Engineering, United Arab Emirates University, P.O. Box 15551 Al Ain, UAE
}

Received: 16 December 2017 / Accepted: 14 May 2018

\begin{abstract}
Building applied solar thermal systems are considered by different stakeholders an attractive alternative to traditional space and water heating systems. However, their performance depends largely on climatic conditions, water heating needs and operational parameters which, in turn, offer opportunities for performance optimization. The present research attempts to provide architects with a design decision tool that integrates solar thermal collectors efficiently to meet hot water demand for various building types inclusive of residential, commercial and industrial in a hot climate. The analysis is conducted numerically through a thermal model developed and executed in TRNSYS and validated experimentally. The parameters investigated include the collector tilt angle, azimuth angle and collector inlet fluid flow rate. Finally, the collector aperture area required per building foot print area is determined. The research revealed that for a $1000 \mathrm{~m}^{2}$ footprint building area of schools, offices, residential, factories and hospitals would require respectively $8 \mathrm{~m}^{2}, 10 \mathrm{~m}^{2}, 14 \mathrm{~m}^{2}, 24 \mathrm{~m}^{2}$ and $38 \mathrm{~m}^{2}$ of the static collector installed at $24^{\circ}$ tilt angle with optimal water flow rate. Additional operational aspects of collector tracking, and solar radiation concentration were investigated and further reduce the required collector area. A simple payback period analysis reveals a return on investment of 2 years applying subsidized tariff rates under the climatic conditions of, or similar to Dubai, in the United Arab Emirates.
\end{abstract}

Keywords: solar water heating systems / building applied / parametric optimization / hot climate / performance assessment

\section{Introduction}

Dubai, in the United Arab Emirates (UAE) increased its energy demand from 33742 to 43093 GWh between 2010 and 2016, while adding $2639 \mathrm{MW}$ electrical power capacity in the same period from 7361 to $10000 \mathrm{MW}$ (Fig. 1) indicating a sharp surge in its energy demand [1]. The capacity addition presented here is solely from gas, oil fired power plants, and does not include renewables. The curve shows that until 2015, the traditional power plants were merely meeting the demand. Afterwards, the demand surpassed the supply. In terms of energy consumption, the commercial sector leads with $47.5 \%$ followed by residential buildings at $28.5 \%$ as illustrated in Figure 2 as of 2016 [1]. This substantial energy needed in buildings contributes to carbon dioxide emissions, heightening the global warming effect [2] that can merely be addressed by integrating sustainable means of energy supply. Out of the total energy consumed in buildings, space and water heating needs range from $81 \%$ in cold climates [3] to $30 \%$ in hot climates [4] which justifies investing into alternative heating

\footnotetext{
* e-mail: kheira.anissa@uaeu.ac.ae
}

solutions to reduce the environmental footprint. The immense solar radiation potential reported in the UAE with measured average daily insolation of $4.98 \mathrm{kWh} / \mathrm{m}^{2}$ and peak intensity ranging between 900 and $1100 \mathrm{~W} / \mathrm{m}^{2}$ in different seasons $[5,6,7]$. These statistics offer a promising source of heat supply through solar systems to meet hot water demand in UAE with the appropriate system sizing and configurations.

The performance of solar-assisted heating and cooling (SHC) systems was compared to the conventional cooling system for two building configurations in the UAE to determine optimal share of solar thermal in the building energy mix. The findings suggest a maximum solar penetration of $20 \%$ that results in an energy and $\mathrm{CO}_{2}$ savings of $176 \mathrm{kWh} /$ year and $140 \mathrm{ton} /$ year with a payback period of 4 years [8]. In another study, the solar thermal collector area and hot water tank volume were optimized for a solar powered absorption cycle under UAE's weather conditions. The findings reveal that a specific collector area of $6 \mathrm{~m}^{2} / \mathrm{kW}_{\mathrm{c}}$ and a specific tank volume of $0.1 \mathrm{~m}^{3} / \mathrm{kW}_{\mathrm{c}}$ offer an optimal design that reduced energy consumption by $47 \%$ and $\mathrm{CO}_{2}$ emissions by 12 tons/year compared to a conventional vapor-compression cooling system [9]. These limited experimental studies conducted in the UAE 


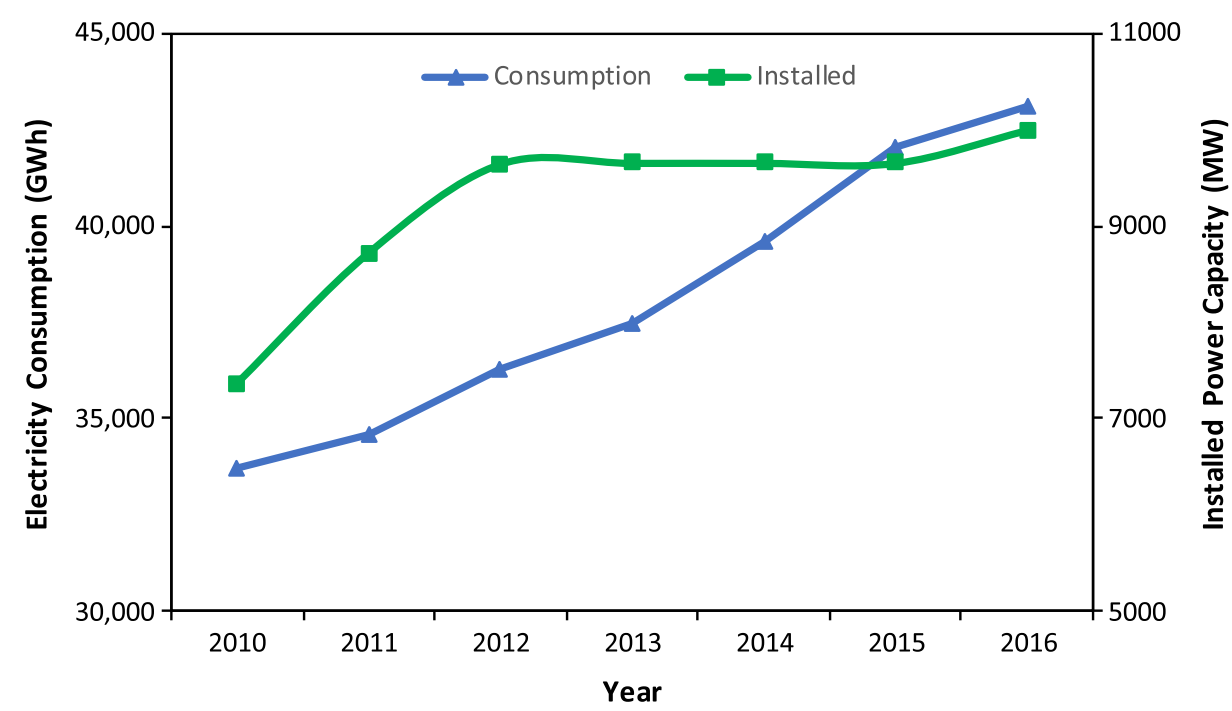

Fig. 1. Growth of electricity consumption and generation in Dubai, United Arab Emirates (UAE) [1].

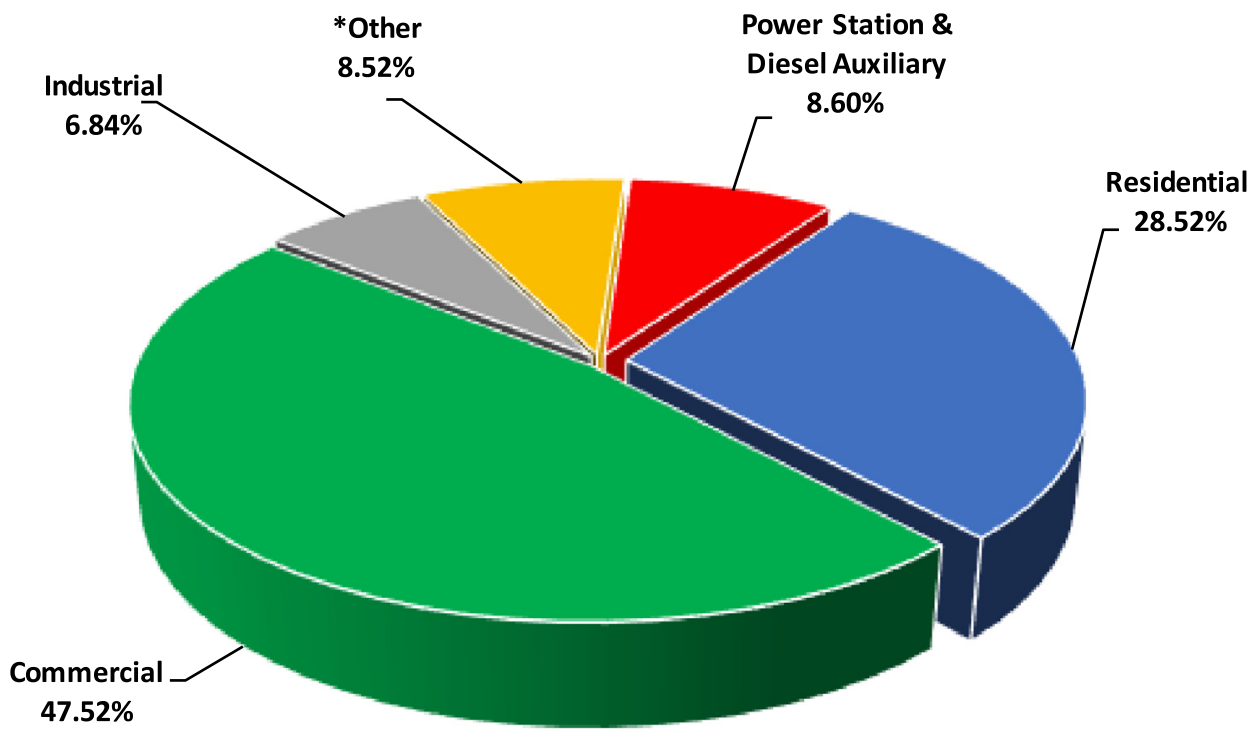

* Other: Non-Commercial (Mosques, Police Stations, Government Hospitals, Government Schools, DEWA Offices, Staff Premises etc.)

Fig. 2. Electricity consumption in different sectors of Dubai, United Arab Emirates (UAE) [1].

revealed that Solar Water Heating Systems (SWHS) are efficient and form an economically viable option to meet the hot water demand in buildings.

However, little is reported about optimal parameters that affect SHW performance inclusive of determining an optimal tilt angle $(\Phi)$ for the main UAE cities (Abu Dhabi and Dubai) [10,11]. This study considered the capital city, Abu Dhabi which lies at a latitude of $\varphi=24^{\circ}$. A detailed parametric optimization investigation is highly needed while considering various hot water demand patterns of different building typology. The current study attempts to numerically investigate collector parameters comprehensively to optimize the collector performance with regard to building types and hot water demands employing a TRNSYS thermal model [12]. The parameters considered include collector tilt angle, azimuth angle and collector inlet fluid flow rate. Additionally, the effect of inlet water temperature, collector tracking and solar radiation concentration were investigated. The objective of this study is to determine design parameters represented by the ratio of collector aperture area to building area for each of the studied building types while assessing its economic viability and system performance.

\section{Methodology}

The transient thermal model developed in TRNSYS is composed of a solar thermal collector and an auxiliary heating source. Simulations were carried out to assess the 
Table 1. Hot water demand and water temperature per building type of a set area of $1000 \mathrm{~m}^{2}$.

\begin{tabular}{llllll}
\hline \multicolumn{1}{c}{ Parameters } & Residential & Hospital & School & Office & Factories \\
\hline $\begin{array}{l}\text { Floor area allowance per } \\
\text { occupant (square meter per }\end{array}$ & 19 & Patient room: 11 & Classroom: 2 & 9 & 9 \\
$\begin{array}{l}\text { person) [13] } \\
\begin{array}{l}\text { Occupant load (Number of } \\
\text { people) }\end{array}\end{array}$ & 53 & 68 & 350 & 111 & 111 \\
$\begin{array}{l}\text { Hot water demand (gallon per } \\
\text { person per day) [14,15] }\end{array}$ & 35 & 35 & 3 & 5 & 10 \\
$\begin{array}{l}\text { Total hot water demand per } \\
\text { building use (gallon per day) }\end{array}$ & 1855 & 2380 & 1050 & 555 & 1110 \\
Water temperature Tr $\left({ }^{\circ} \mathrm{C}\right)[13]$ & 45 & 65 & 45 & 45 & $70-110$ \\
\hline
\end{tabular}

contribution and effectiveness of SWHS in meeting specific hot water demands in various building types. The building types considered include residential, schools, hospitals, offices and factories. For this investigation and comparison, all building types are considered to be $1000 \mathrm{~m}^{2}$ in size. Buildings with spatially different occupant loads, such as hospitals and schools, have been considered accordingly, with half of the building area dedicated to each. The occupant load, water demand and required water temperature are calculated from relevant codes $[13,14]$. Table 1 summarizes the input data parameters.

\subsection{Simulation model set up}

The flat-plate solar collector is simulated using Hottel-Whillier steady-state model [16] which predicts the heat gain as a function of collector aperture area $\left(A_{c}\right)$, number of identical collectors $\left(n_{c}\right)$ and weather conditions as presented in equation (1);

$$
Q_{c}=\frac{A_{c}}{n_{c}} \sum_{k=1}^{n_{c}} f_{r, k}\left[I_{t i}(\tau \alpha)-U_{c, k}\left(T_{i, k}-T_{a}\right)\right]
$$

The model employs overall energy gain efficiency factor $\left(f_{r}, k\right)$, total incident solar radiation $\left(I_{t i}\right)$, collective losses $\left(U_{c}, k\right)$, temperature of fluid entering the collector $\left(T_{i}\right)$ and ambient temperature $\left(T_{a}\right)$ to calculate collector heat gain $\left(Q_{c}\right)$. The $f_{r}, k$ is an exponential function of the collector aperture area and thermal capacity $\left(C_{p c}\right)$ as given in equation (2);

$$
f_{r, k}=\frac{n_{c} m_{c} c_{p c}}{A_{c} U_{c, k}}\left(1-e^{-\frac{f_{c} U_{c, k} A_{c}}{n_{c} m_{c} c_{p c}}}\right) .
$$

The product of transmittance and absorptance of the collector absorber plate for beam radiation $(\tau \alpha)_{b}$, diffusedradiation $(\tau \alpha)_{d}$, and ground reflectance $(\tau \alpha)_{g}$ are calculated by the trigonometric co-relation considering collector relative position to the incoming solar radiation given in equation (3);

$$
\tau \alpha=\frac{I_{b}(\tau \alpha)_{b}+I_{d}\left(\frac{1+\cos \beta}{2}\right)(\tau \alpha)_{d}+r_{g} I_{t}\left(\frac{1-\cos \beta}{2}\right)(\tau \alpha)_{g}}{I_{T}} .
$$

$\left(U_{c}, k\right)$ is overall loss-coefficient by Klein composed of radiation and convection from top and bottom collector surfaces [16]. These losses are a function of number of glass covers $\left(n_{g}\right)$, collector fin efficiency $\left(f_{c}\right)$, number of collectors $\left(n_{c}\right)$, Stefan Boltzmann's constant $(\sigma)$, emissivity of glass cover $\left(\epsilon_{g}\right)$, absorber plate emittance $\left(\epsilon_{p}\right)$ and loss coefficients for edges and bottom $\left(U_{b e}\right)$ as depicted in equation (4).

$$
\begin{aligned}
U_{c, k}= & \frac{3.6}{n_{g}}\left\{\left[\frac{c}{T_{p, k}}\left(\frac{T_{a v, k-T_{a}}}{n_{g}+f}\right)\right]^{0.33}+\frac{1}{h_{w}}\right\} \\
& +\frac{3.6 \sigma\left(T_{a v, k}^{2}+T_{a}^{2}\right)\left(T_{a v, k}+T_{a}\right)}{\frac{1}{\varepsilon_{p}+0.05 n_{g}\left(1-\varepsilon_{p}\right)}+\frac{2_{n g}+f-1}{\varepsilon_{g}} n_{g}}+U_{b e} .
\end{aligned}
$$

The stratified thermal storage tank with variable inlets conditions is employed having an immersed coiled heat exchanger, with five segments for thermal lamination. The temperatures of hot water tank at the outer side $\left(T_{h w 2}\right)$ and average temperature at inner side $\left(T_{h w a}\right)$ were calculated by using equations (5) and (6) [17].

$$
\begin{gathered}
\frac{d T_{\mathrm{tank}}}{d t}=\frac{Q_{\mathrm{in}, \mathrm{tank}}-Q_{\mathrm{out}, \mathrm{tank}}}{c_{\mathrm{tank}}}, \\
\frac{d T_{H X}}{d t}=\frac{Q_{\mathrm{in}, H X}-Q_{\mathrm{out}, H X}}{c_{H X}},
\end{gathered}
$$

where $Q_{\text {in,tank }}$ and $Q_{\text {out,tank }}$ depend on heat exchanger temperature, ambient temperature and solar irradiation. The $Q_{\mathrm{in}, \mathrm{HX}}$ and $Q_{\mathrm{out}, \mathrm{HX}}$ depend on inlet fluid temperature and tank temperature. The temperatures $T_{h w 2}$ and $T_{h w a}$ are calculated by opting equations (7) and (8).

$$
\begin{gathered}
T_{h w 2}=\left(T_{h w 1}+\frac{b_{\text {ave }}}{a}\right) e^{a \Delta t}-\frac{b_{\text {ave }}}{a}, \\
T_{h w a}=\frac{1}{a \Delta t}\left(T_{h w 1}+\frac{b_{\text {ave }}}{a}\right)\left(e^{a \Delta t}-1\right)-\frac{b_{\text {ave }}}{a},
\end{gathered}
$$

where $a$ and $b$ are the coefficients of the differential equation in the form $d T / d t=a T+b$ and $b_{\text {ave }}=b T_{\text {ave }}$. 


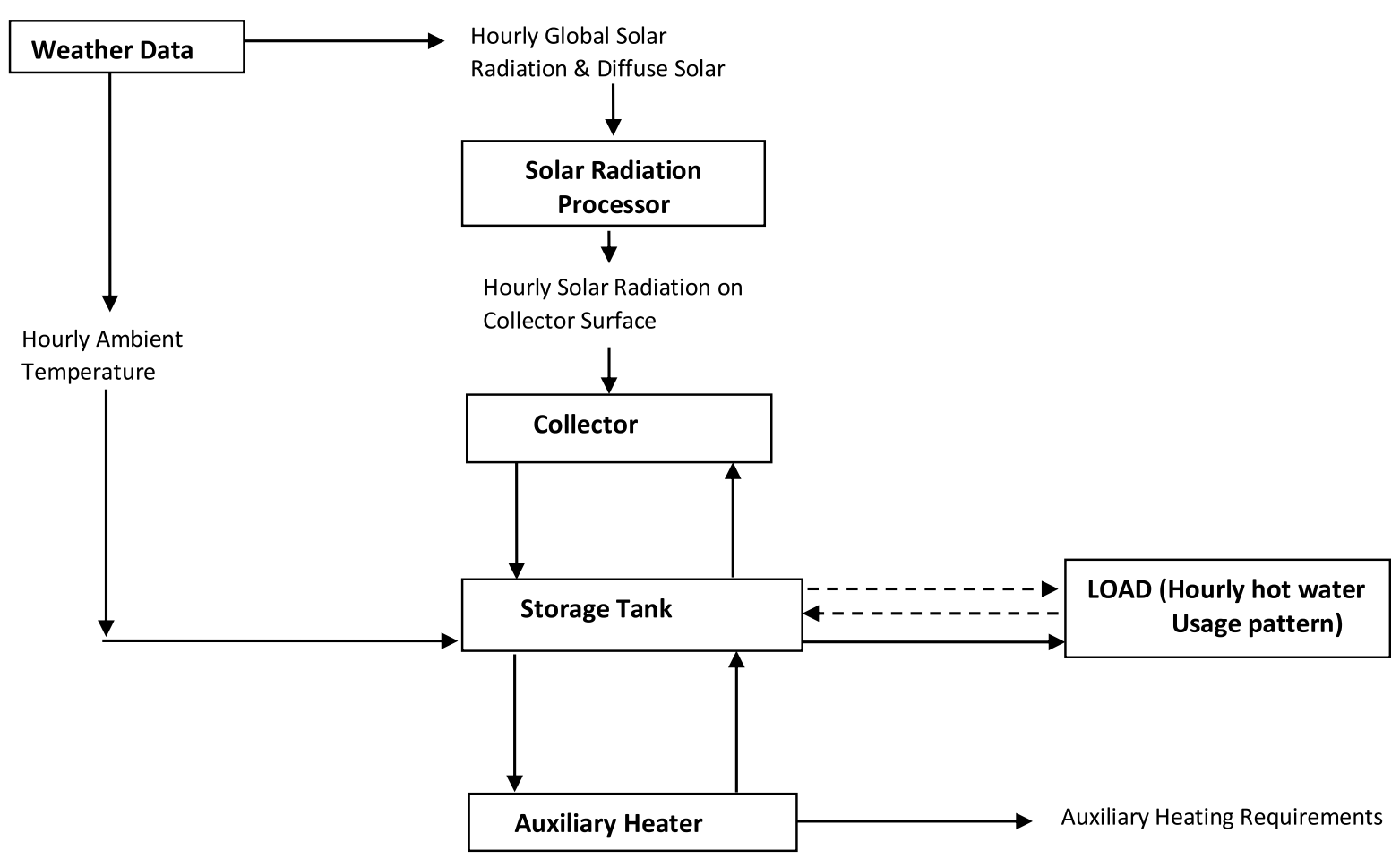

Fig. 3. Information flow diagram of micro-simulation for SWHS [19].

Figure 3 shows the information flow diagram for the micro-simulation of solar water heating and Figure 4 shows the flow diagram of TRNSYS for SWHS. The components of the SWHS considered are flat plate solar collector, water pump, storage tank and auxiliary electric heater. The system comprises of a $2 \mathrm{~m}^{2}$ flat-plate collector with $1 \mathrm{HP}$ water pump and 325 gallons of water tank. A simulation model predicted the long-term thermal performance of the FPC.

The literature findings show that solar collector efficiency varies from 40 to $60 \%$ [18] as a function of inlet and ambient conditions as shown in Figure 5 [19]. The inputs for simulation include hot water usage pattern, system specifications and weather data. The time resolved weather data of interest is processed in "weather" block to feed into the thermal model represented by "collector". A feedback ON-OFF control loop is in place between the collector outlet and demand side temperature $\left(T_{\text {tank }}\right)$ shown by the "controller" block to trigger water through collector by sensing tank temperature and availability of resource (solar radiation).

\subsection{Building typology}

The building typology is defined by hot water use pattern and set point temperatures in the present study. In literature, several standard hot water usage patterns are reported for the US and Europe [20,21], while very little is available on the subject for hot weather as of UAE. The pattern shown in Figure 6 is used to estimate a standard demand for residential, hospital and office buildings [22-24] in the UAE. In the current simulations, the end use temperature is set at $45^{\circ} \mathrm{C}$ for residential, school and office buildings and $65^{\circ} \mathrm{C}$ for hospital buildings.

\section{Results and discussion}

The thermal model developed in TRNSYS is validated with experimental data measured from a flat plate collector installed at the same site. Simulations are conducted employing typical means year (TMY-2) weather data for Abu Dhabi. The collector operational parameters of tilt angle, heat transfer fluid flow rate and heat loss coefficients are set in the TRNSYS model representing the experimental set up and ambient conditions. Temperatures were measured at front surface and leaving water from the collector and compared with the model prediction as shown in Figure 7. The results show a reasonable agreement between experimental and simulated temperatures with deviation of less than $5 \%$ at the most. The validated model is used to predict effects of collector operational parameters on the energy produced from the collector presented in the following sections.

\subsection{Collector tilt angle}

The performance of solar collector depends on its inclination angle [25,26]. Designers generally locate collectors on the building roof (pitched or flat) or on the façade (vertical wall). The same is simulated by varying monthly collector tilt angle $(\Phi)$ from $0^{\circ}$ (representing flat roof) to $90^{\circ}$ (representing south facing façade) with an increment of $5^{\circ}$ representing various roof pitch angles while keeping at $0^{\circ}$ azimuth representative of a south facing collector in the northern hemisphere. The average thermal gain $\left(Q_{c}\right)$ is plotted against $\Phi$ as shown in Figure 8 to determine the optimal $\Phi$ for each month. The $Q_{c}$ for January (winter) was $1.95\left(\mathrm{kWh} / \mathrm{m}^{2}\right)$ at $\Phi$ of $0^{\circ}$ which 


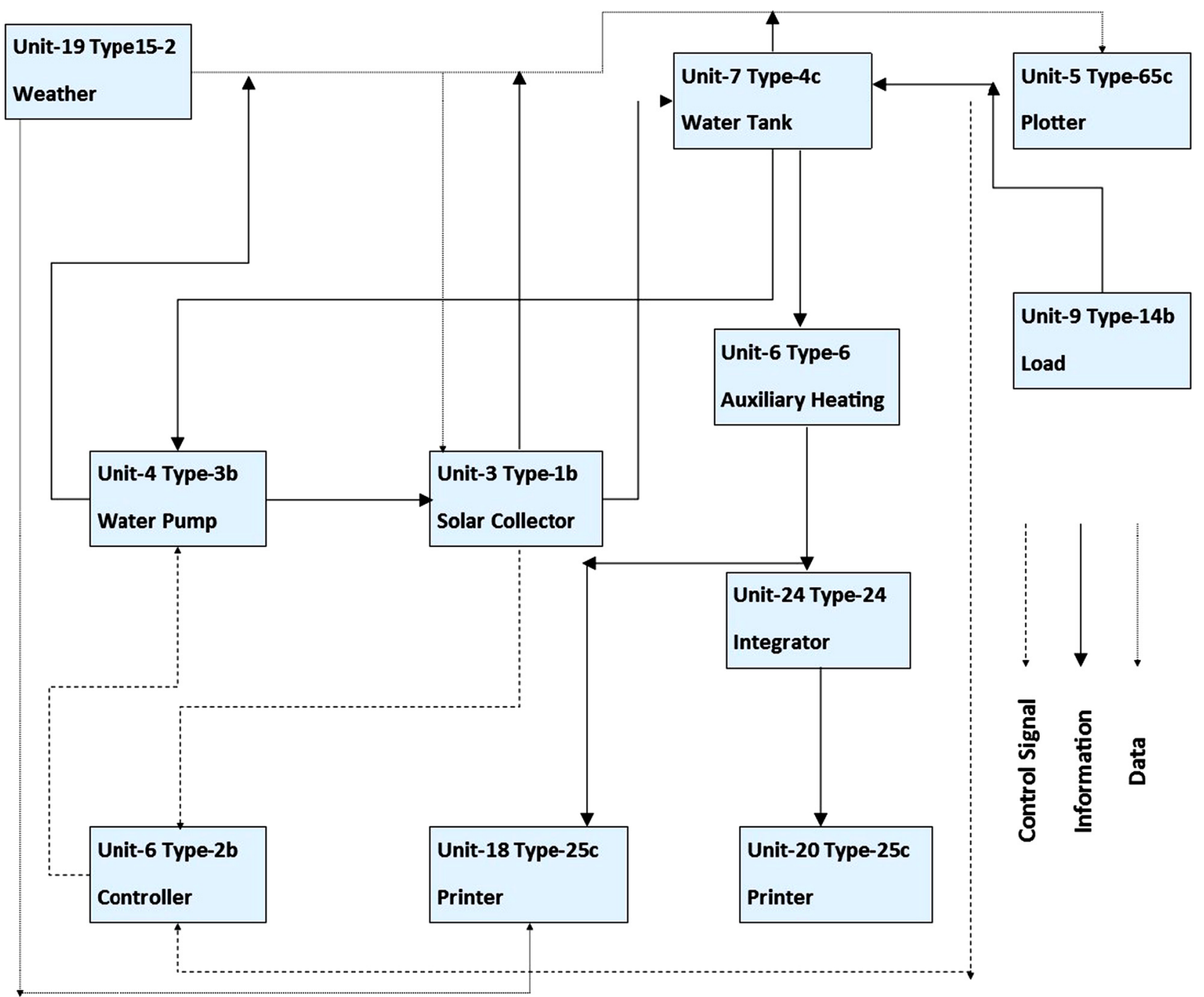

Fig. 4. Information flow diagram of TRNSYS for SWHS.

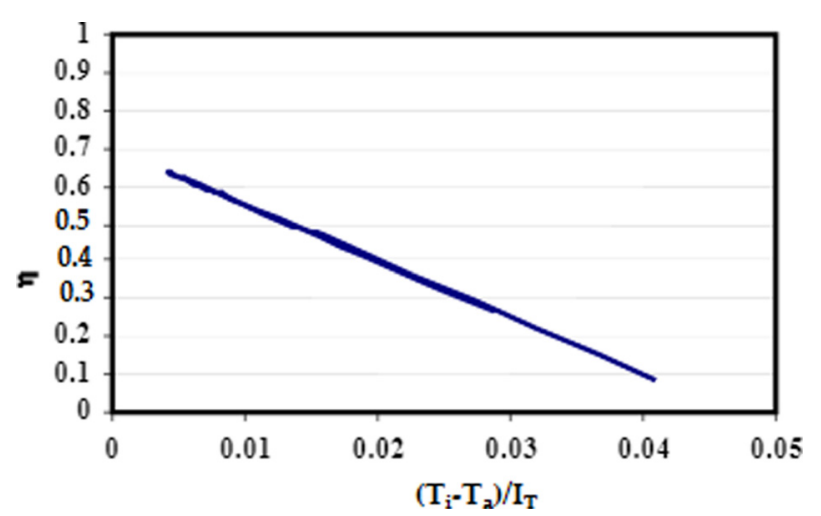

Fig. 5. Solar collector efficiency curve [19].

kept increasing to reach at $3.25\left(\mathrm{kWh} / \mathrm{m}^{2}\right)$ at $\Phi$ of $50^{\circ}$ (pitched roof). Beyond $50^{\circ}$, it kept dropping to reach to $2.2\left(\mathrm{kWh} / \mathrm{m}^{2}\right)$ at $\Phi$ of $90^{\circ}$ (vertical wall). It can be deduced that $50^{\circ}$ is the optimal pitch angle for south-facing collector in January for Abu Dhabi. Similarly, for summer months i.e. May, the average $Q_{c}$ was $4.11\left(\mathrm{kWh} / \mathrm{m}^{2}\right)$ at $\Phi$ of $0^{\circ}$ which kept decreasing with increasing $\Phi$ to reach 0.75 $\left(\mathrm{kWh} / \mathrm{m}^{2}\right)$ at $90^{\circ}$, suggesting that $0^{\circ}$ is the optimal $\Phi$ in May. Similarly, the optimal $\Phi$ for each month was determined based on maximal $Q_{c}$ presented in Table 2.

To determine the yearly optimal fixed pitch angle, the collector slope was varied from 12 to $36^{\circ}$ to simulate the offlatitude collector performance by up to $\pm 12^{\circ}$. The maximum yearly $Q_{c}$ of $1207.47\left(\mathrm{kWh} / \mathrm{m}^{2}\right)$ was obtained at $24^{\circ}$, the latitude of the place as shown in Figure 9 , which agrees with previous findings [27]. The findings highlight that the collector performance can greatly be optimized by monthly adjustment of $\Phi$ instead of yearly fixed value with little to no additional cost while bringing substantial benefits.

The architects may encounter design-dictated situations to install collectors either as wall mounted (for high rise buildings) or roof installed (sloped or flat). Hence, knowing the compromise between the design preferences and the prospective energy production would be informative. Thus, the yearly thermal performance of the collector installed at a sloped roof of $\left(24^{\circ}\right)$, flat roof $\left(0^{\circ}\right)$ and vertical 

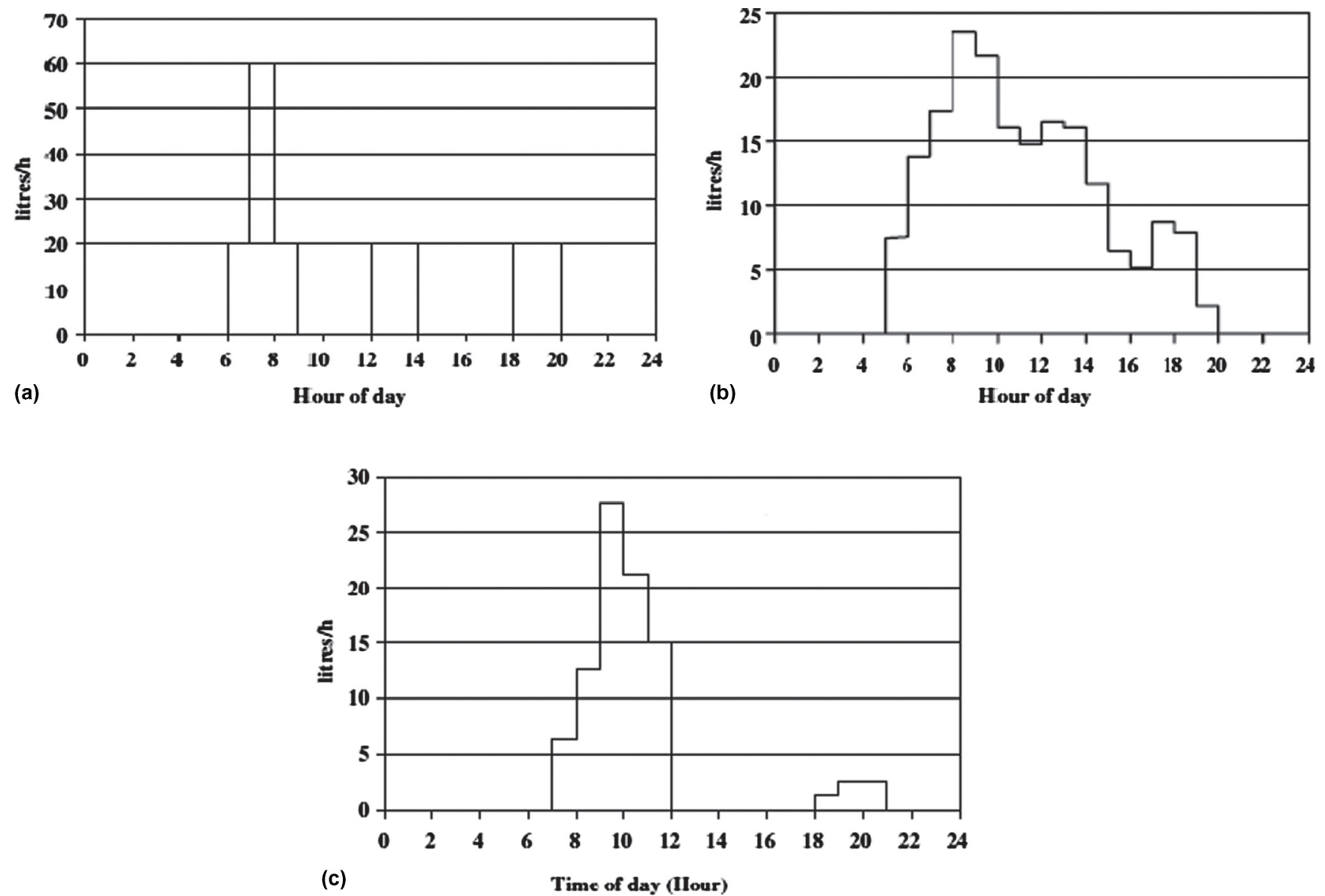

Fig. 6. Hot water usage pattern for (a) residential (b) hospital (c) office [22-24] under the hot weather conditions as of UAE.

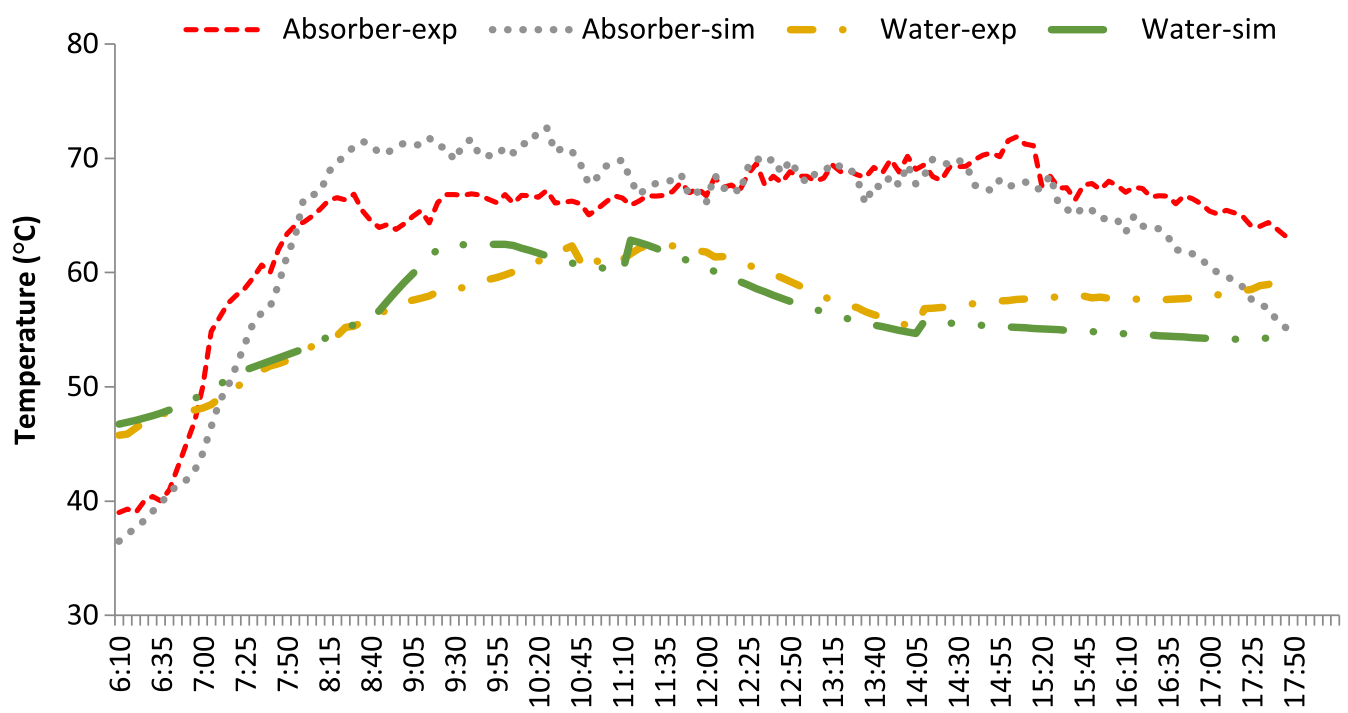

Fig. 7. The experimental and simulated temperatures of the absorber surface and water leaving the collector.

wall $\left(90^{\circ}\right)$ are compared in Figure 10 . The results show that the collector installed on a sloped roof (latitude angle) performed the best, followed closely by the flat roof. The collector performance varied slightly with building type mainly due to effect of water flow rate.

\subsection{Azimuth angle}

The optimal orientation is determined as south facing at zero azimuth $(\beta)$. However, at times, designers are required to apply collectors deviating from south that may affect $Q_{c}$ 


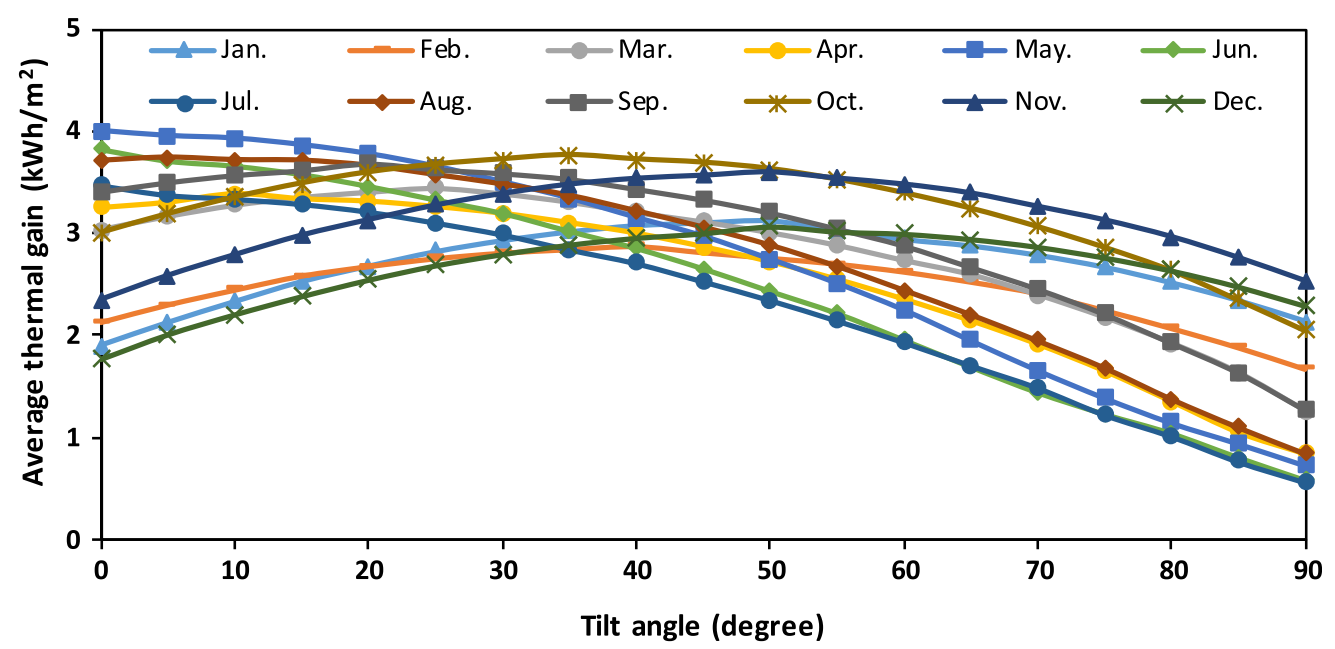

Fig. 8. Monthly average thermal energy $\left(Q_{c}\right)$ produced by solar collector at various tilt angles $(\Phi)$.

Table 2. Optimum monthly collector tilt angles for enhanced thermal energy gain.

\begin{tabular}{lcl}
\hline Month & $\Phi_{\text {opt }}$ & Thermal gain $\left(Q_{c}\right)$ \\
\hline Jan & 50 & 3.23 \\
Feb & 40 & 2.97 \\
Mar & 25 & 3.58 \\
Apr & 10 & 3.59 \\
May & 0 & 4.11 \\
Jun & 0 & 3.93 \\
Jul & 0 & 3.57 \\
Aug & 5 & 3.87 \\
Sep & 20 & 3.81 \\
Oct & 35 & 3.86 \\
Nov & 50 & 3.72 \\
Dec & 50 & 3.18 \\
Average & 23.75 & 3.62 \\
\hline
\end{tabular}

[28]. The impact of varying $\beta$ from $90^{\circ}$ (east) to $-90^{\circ}$ (west) with an increment of $30^{\circ}$ was, therefore, determined on $Q_{c}$ on a monthly and yearly basis as shown in Figure $11 \mathrm{~A}$ and B. The results indicate that $Q c$ peaked at $\beta=0^{\circ}$ for all months. An interesting observation noted that in summer months (April to August) the collector performance remained unaffected by azimuth changes while during the rest of the year (September to March) the performance decreased sharply when moving away from the south orientation. Hence, yearly $Q_{c}$ of the south facing collector is $30 \%$ and $22 \%$ higher than that of west and east facing collector respectively.

\subsection{Inlet flow rate}

Daily water consumption for each building type is calculated per code requirements to size the collector tank and is kept fixed for the whole year. Since the collector only recovers thermal energy during the daytime, the varying daylight intensity and hours affect the amount of thermal energy available at the collector. The variable energy available at the absorber requires variable water flow rate for optimal energy recovery. The water flow rate inlet to the collector will in turn need to be optimized for different months. The total daily water demand is circulated through the collector during daytime (represented by daylight hours) at various flow rates to determine optimal flow rate for each month and building type. The summer months of May and June had the highest number of daylight hours with an average of $13 \mathrm{~h}$, while the winter months of January and December had the lowest with an average of $10 \mathrm{~h} \mathrm{[29].} \mathrm{On} \mathrm{the} \mathrm{other} \mathrm{hand,} \mathrm{the} \mathrm{heating} \mathrm{demand}$ naturally peaked in winter months compared to that of summer months. Additionally, each building type has different occupant loads and temperature set points which impact the optimal water flow rate for maximum thermal energy recovery. The inlet water flow rate for each of the building sector considered (residential, hospital, school, office, factories) is optimized for each month considering all the above-mentioned factors. Inlet water flow rate was found to be higher in winter months and lower in summer months yielding maximal thermal energy extraction as shown in Figure 12 while the hospital building required the highest and the most variable water flow rate.

\subsection{Inlet water temperature}

Since temperature of municipality supply water entering the collector is an uncontrolled parameter, its influences on the collector's performance is of interest specifically in UAE as it varies substantially among different seasons. The inlet water is assumed to be 3 to $4{ }^{\circ} \mathrm{C}$ higher than average daytime ambient temperature $\left(T_{\text {avg-amb-day }}\right)$ considering the effect of ambient temperature and solar flux on the exposed storage tanks [30]. The $T_{\text {avg-amb-day }}$ in UAE was the highest in May $\left(42^{\circ} \mathrm{C}\right)$ and the lowest in January $\left(26^{\circ} \mathrm{C}\right)[7] . Q_{c}$ for each building type is plotted (left axis) with $T_{\text {avg-amb-day }}$ (red line on right axis) as presented in Figure 13. At the lowest $T_{\text {avg-water-inlet }}, Q_{c}$, is the highest 


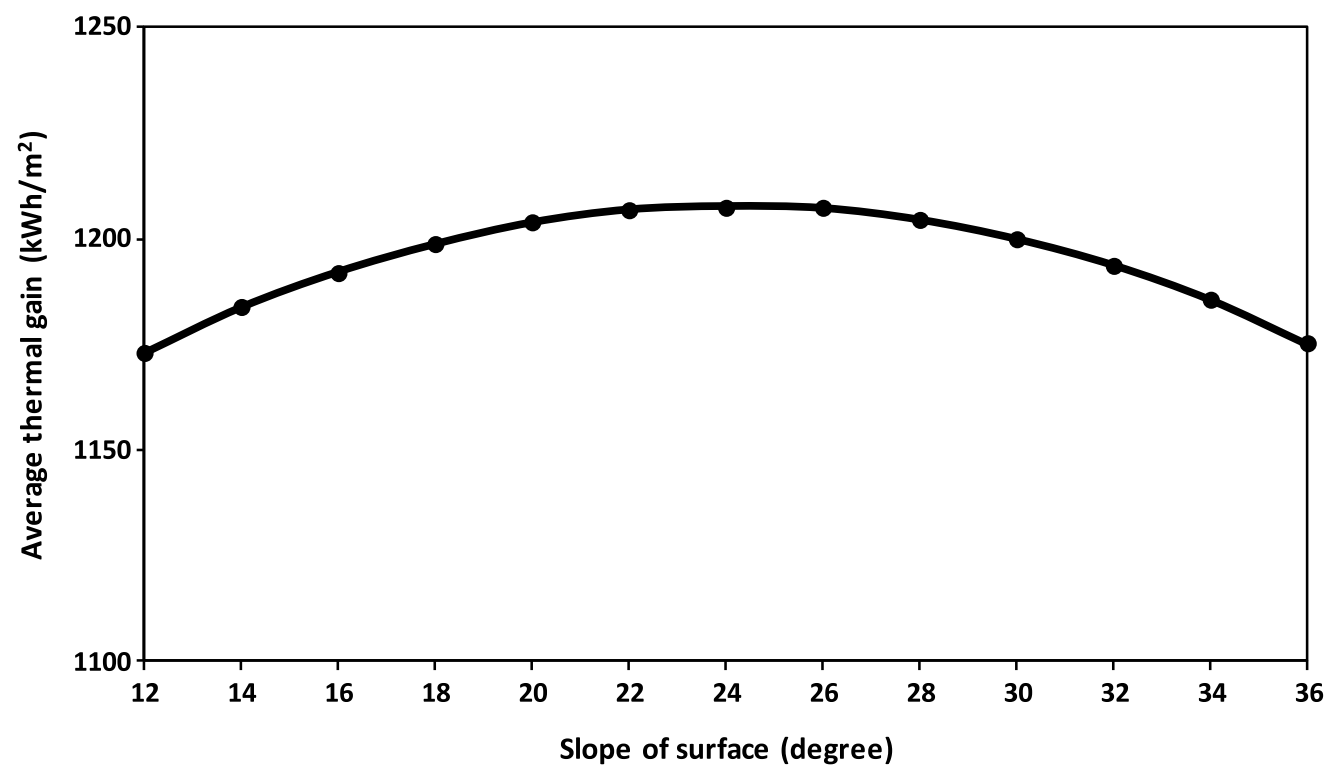

Fig. 9. Yearly thermal energy gain $\left(Q_{c}\right)$ of the collector at various tilt angles $(\Phi)$ to determine energy losses at the off optimal latitude scenarios.

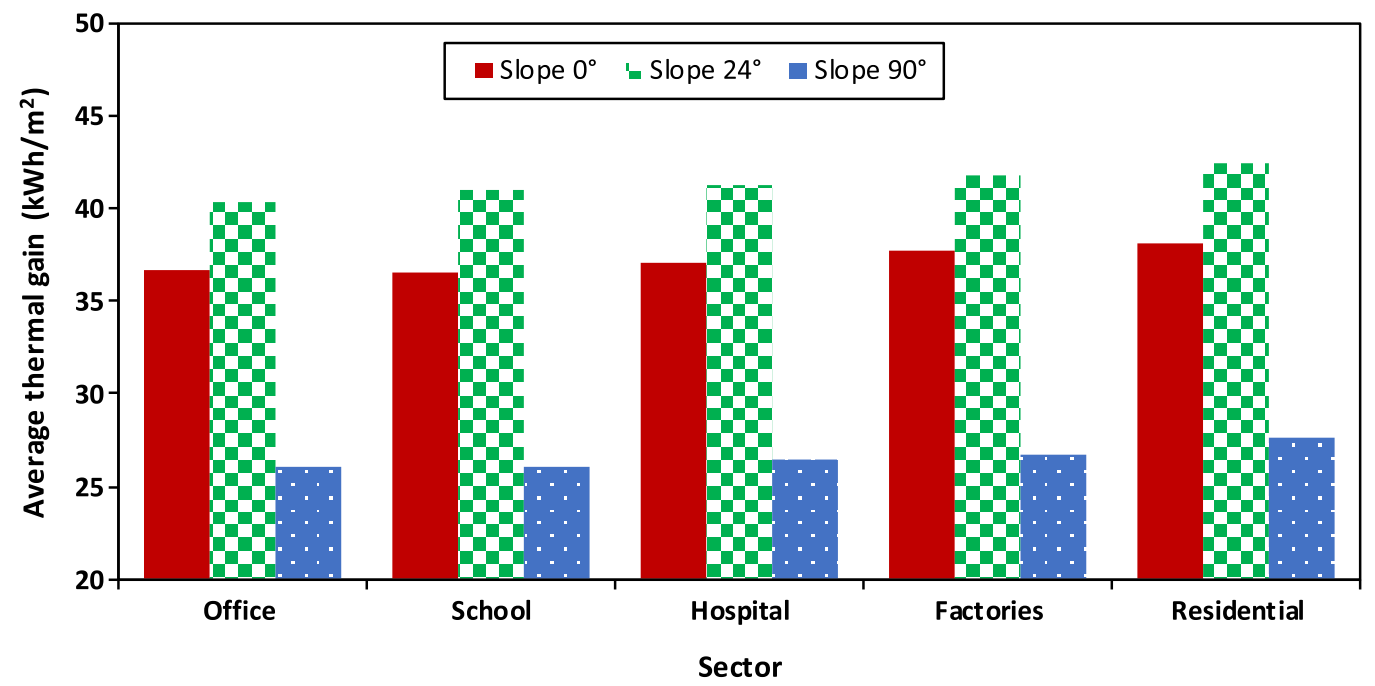

Fig. 10. Thermal energy gain $\left(Q_{c}\right)$ of the collector installed at the pitched roof $\left(24^{\circ}\right)$, flat roof $\left(0^{\circ}\right)$ and vertical wall $\left(90^{\circ}\right)$.

and the vice versa which is in agreement with the collector efficiency curve shown in Figure 5. The results shown in Figure 13 confirm that the collector delivered higher thermal energy from September to April which coincides with the peak months of hot water demand. The occurrence of demand and supply peaks in the same season enabling the stakeholder to utilize maximum collector capacity.

\subsection{Solar tracking}

The regular building applied collectors for office, residential and commercial sectors were not tracked while tracking was considered for hospitals. However, the strong and stable radiation spanning over several daylight hours in UAE and similar contexts offers an opportunity to determine the potential enhancement in collector yield through solar tracking. The effect of solar tracking is investigated employing three tracking modes i.e., the surface rotates about a vertical axis (single-axis) to track the sun (track-1), the surface rotates about horizontal axis (single-axis) to track the latitude changes (track-2), the surface tracks in horizontal and vertical axis (double-axis) such that the beam radiation is always normal to the surface (track-3). The $Q_{c}$ of tracked collector is compared with that of a static collector facing south at optimal tilt angle $\left(24^{\circ}\right)$. The net $Q_{c}$ produced by collector in each tracking mode is calculated after subtracting the energy required for tracking of the collector and is presented in Figure 14 . The net $Q_{c}$ for track-1, track-2, and track-3 was higher than that of static collector by $5.6 \%, 10.3 \%$ and $13.4 \%$ respectively indicating a potential to introduce tracking option. The simulation studies are pure energy 

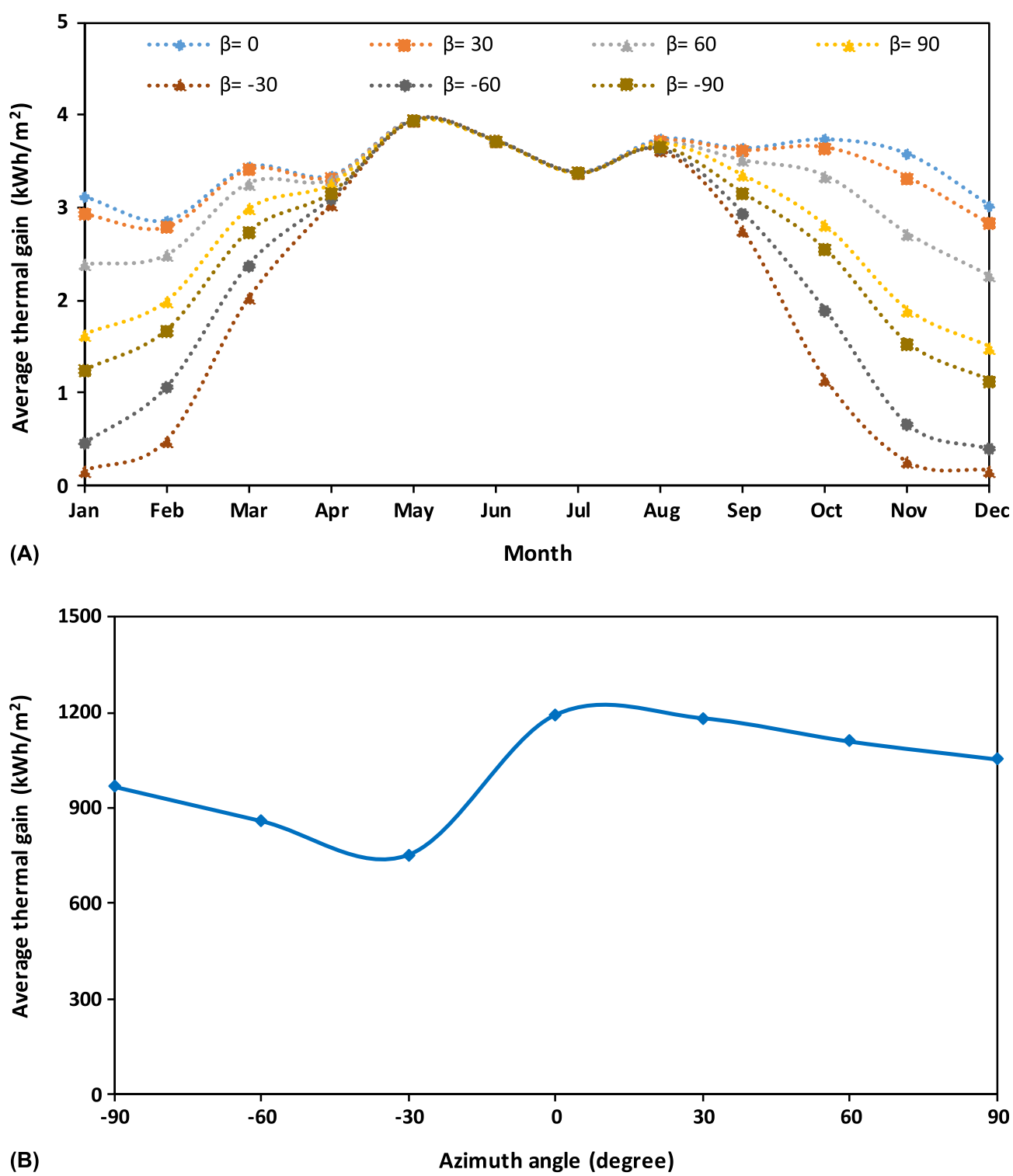

Fig. 11. (A) The impact of azimuth angle $(\beta)$ on the average energy produced from the solar collector $\left(Q_{c}\right)$ on average monthly basis. (B) The impact of azimuth angle $(\beta)$ on the energy produced from the solar collector $\left(Q_{c}\right)$ on yearly basis.

comparisons and does not include the special and structural requirements of tracking systems which needs further analysis and is out of the scope of this paper.

\subsection{Solar concentration}

The solar radiation as it reaches the collector surface (so called single sung) yields lower temperatures suitable for building applications that require water at $45^{\circ} \mathrm{C}$. However, for hospitals and industrial processes, the required temperatures range from 75 to $110^{\circ} \mathrm{C}$ and is unlikely to be achieved by the conventional single sun collectors. To achieve such a higher temperature, modifications are required such as adding mirrors or lenses to concentrate solar radiation. The effect of solar concentration by employing geo-metrical concentration ratio (ratio of lenses or mirror area to the collector area) ranging from 1 to $5 \mathrm{x}$ are investigated in winter months (Dec. and Jan.) to determine their effectiveness in the worst-case scenario i.e., season of higher water demand with lower solar gains. An almost linear increase in collector outlet temperature was observed with increasing solar radiation concentration as shown in Figure 15. It was observed that without solar concentration (1x), the water temperature remained below $60^{\circ} \mathrm{C}$ which can only serve domestic buildings with demand side temperature of $45^{\circ} \mathrm{C}$. The temperature required for hospital buildings $\left(65^{\circ} \mathrm{C}\right)$ is achieved with the concentration ratio of $2 \mathrm{x}$ and that required for industrial buildings $\left(70^{\circ} \mathrm{C}-110^{\circ} \mathrm{C}\right)$ is achieved by concentration ratio of $3-5 \mathrm{x}$. To achieve such temperatures, the collector needs modifications such as optical elements, tracking systems and structural support which involves additional space and cost which are not considered at this stage. The study therefore, is intended to determine achievable temperatures at certain concentra- 


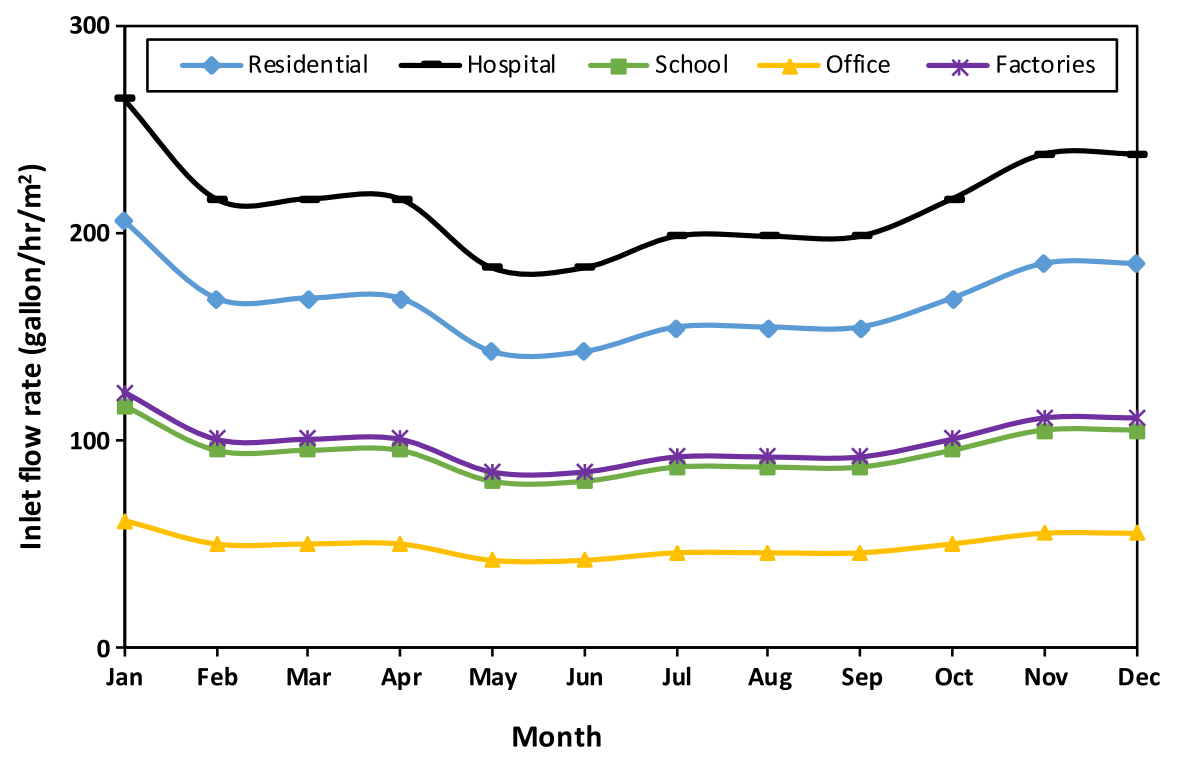

Fig. 12. Monthly average inlet water flow rate for different building type.

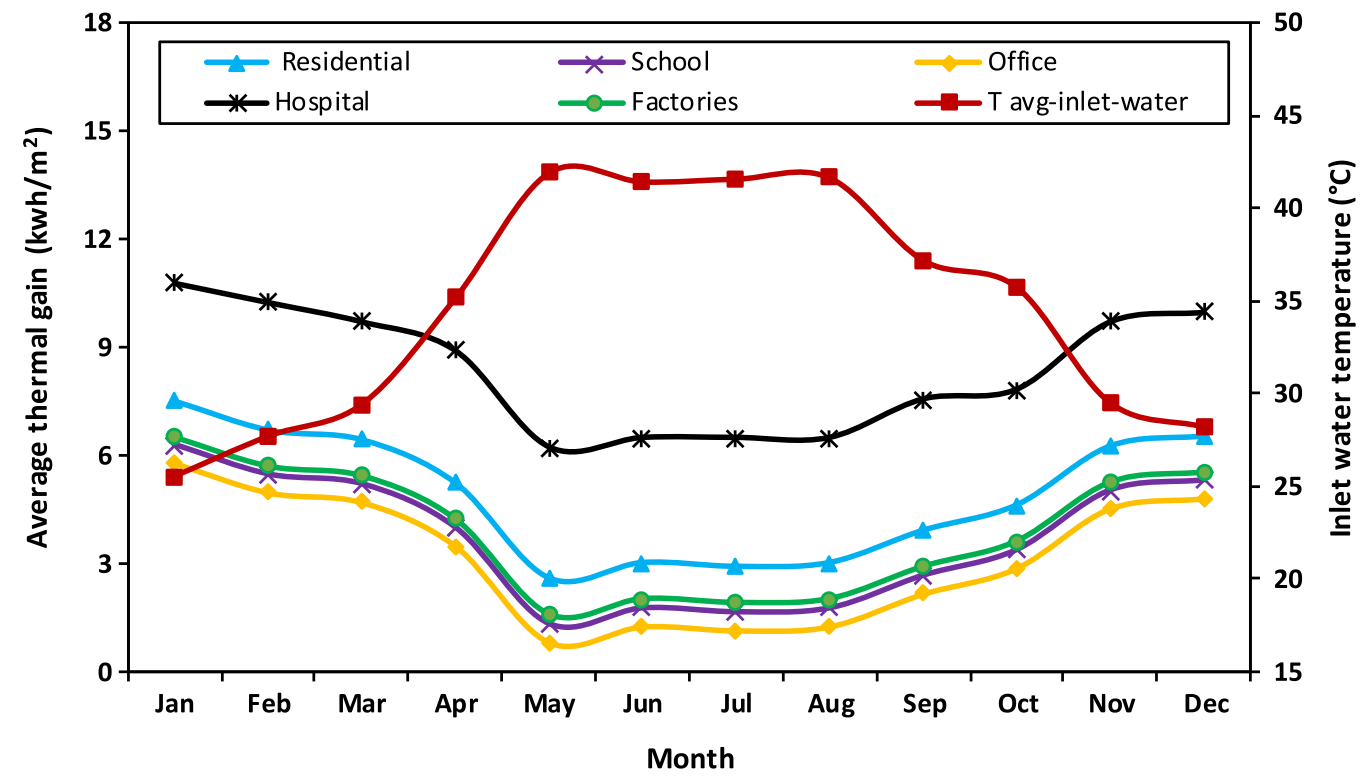

Fig. 13. Average energy contribution from the solar collector with varying inlet water temperature.

tion ratios only leaving the detailed resource input-output comparison for future studies.

\section{Overall system performance}

Finally, the collector is simulated using optimal collector parameters of tilt angle, azimuth angle and water flow rate discussed in previous sections to determine its effectiveness in delivering the required amount of hot water [14] and at the desired temperature [15]. The thermal energy produced by the collector is compared to the thermal energy required by each building type for the required amount of hot water production. Finally, the ratio of collector area to building foot print area is calculated to deliver the required hot water demand for each building type as shown in Table 3. The results show that the hospital building required the highest collector area per building area associated to higher occupants' density as well as hot water demand for specific activities such as equipment sterilization.

The calculated ratios should help building professionals and owners to size an optimal solar thermal collector for their respective buildings with minimal effort and yet be accurate. In design terms, however, opportunities may be sometimes limited, knowing that SWHS are traditionally installed on rooftops, the space availability may be limited due to building design (for example, in tall buildings) or the existence of other building equipment such as HVAC systems. The reported higher temperatures achieved by solar tracking and solar concentration can widen the 


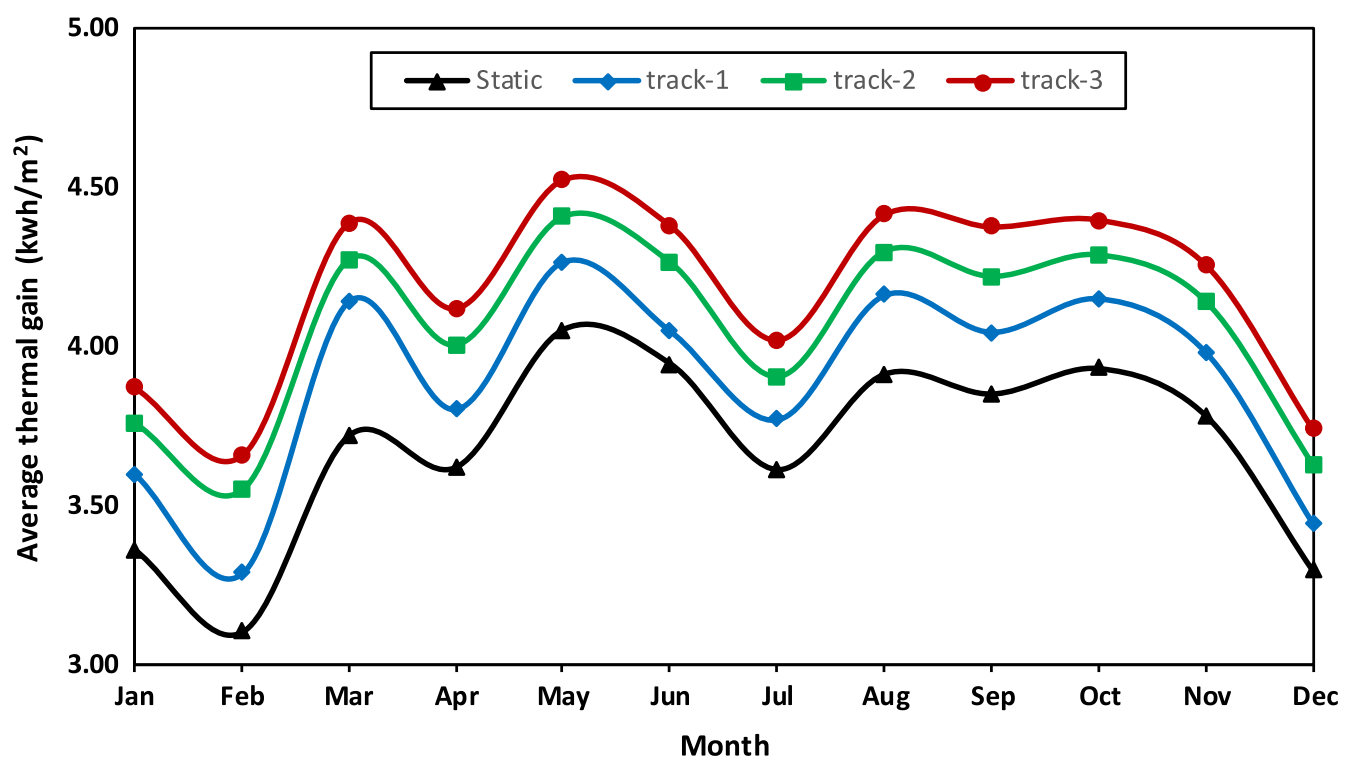

Fig. 14. Monthly average energy contribution from the solar collector with varying solar tracking modes.

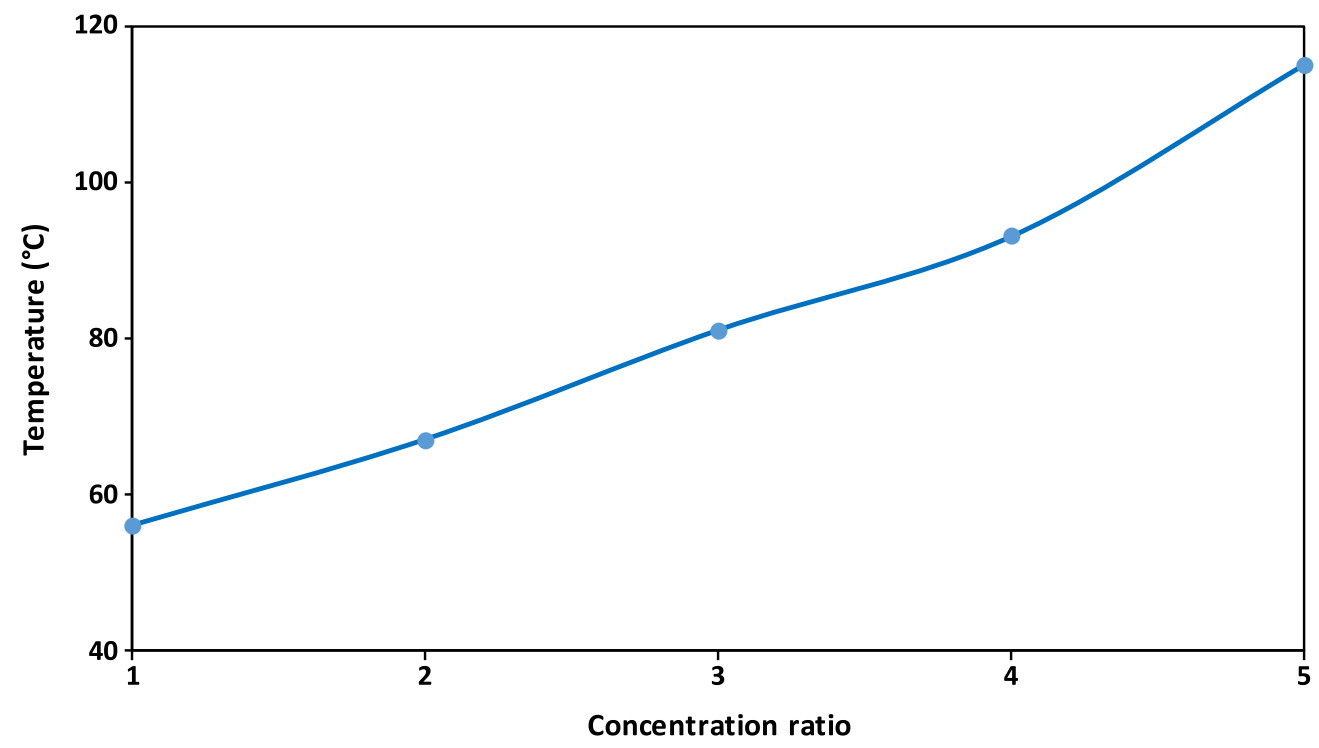

Fig. 15. Temperature variation versus solar radiation concentration.

integration of solar energy in novel areas like industries, nevertheless it comes at the expense of additional space by concentrators and tracking systems.

\section{Economic analysis of the system}

The economic analysis is conducted by calculating simple payback period considering the benefit of energy produced and the cost of the systems installed. The energy is converted into monetary cost and benefit by applying UAE based electricity tariff of AED $0.32 / \mathrm{kWh}$ [31]. To apply the electrical energy tariffs, the thermal energy is converted into equivalent electrical energy by considering a $70 \%$ depreciation in energy quality. Additional tracking, inclusive of tracking system and energy, cost is counted as $\$ 0.36$ per watt installed [32] considering thermal systems equivalent of PV systems in terms of tracking. Energy consumed by the pump to circulate water through collector is calculated by assuming $10 \mathrm{~m}$ additional water head with a flow rate of $0.18 \mathrm{~L} /$. It resulted in the additional shaft power of $30 \mathrm{~W}$ for pumping. The equivalent electrical energy gain for static, single axis tracked (vertical), single axis tracked (horizontal), double axis tracked, and concentrated case is $35.3 \mathrm{MWh} /$ lifetime, $37.5 \mathrm{MWh} /$ lifetime, $\quad 39.2 \mathrm{MWh} /$ lifetime, $\quad 40.6 \mathrm{MWh}$ /lifetime and $50.6 \mathrm{MWh}$ /ifetime respectively. The considered costs and benefits are compiled in Table 4 . 
Table 3. Energy performance of the optimized solar thermal collector for various building types under different tracking options.

\begin{tabular}{clcccc}
\hline Sector & \multicolumn{1}{c}{ Parameters } & Static & $\begin{array}{c}\text { Single axis } \\
\text { tracking (vertical) }\end{array}$ & $\begin{array}{c}\text { Single axis } \\
\text { tracking (horizontal) }\end{array}$ & $\begin{array}{c}\text { Double axis } \\
\text { tracking }\end{array}$ \\
\hline Residential & Energy demand (MJ/day) & 558 & - & - & - \\
& Energy produced (MJ/day) & 157 & 165 & 172 & 178 \\
& No of collector required & 7 & 7 & 6 & 6 \\
& Collector area per building area & 0.0142 & 0.0135 & 0.0129 & 0.0125 \\
& & & & & - \\
Hospital & Energy demand (MJ/day) & 1470 & - & 168 & 173 \\
& Energy produced (MJ/day) & 152 & 161 & 17 & 0.0340 \\
& No of collector required & 19 & 18 & 0.0349 & - \\
& Collector area per building area & 0.0385 & 0.0365 & - & 172 \\
& & & & 167 & 3 \\
School & Energy demand (MJ/day) & 315 & - & 4 & 0.0073 \\
& Energy produced (MJ/day) & 151 & 160 & 0.0075 & - \\
& No of collector required & 4 & 4 & - & 77 \\
& Collector area per building area & 0.0083 & 0.0079 & 75 & 4 \\
& & & & 4 & 0.0086 \\
& Energy demand (MJ/day) & 166 & - & 0.0089 & - \\
& Energy produced (MJ/day) & 68 & 72 & - & 17 \\
& No of collector required & 5 & 5 & 0.0222 & 0.0216 \\
\hline
\end{tabular}

Table 4. Cost estimation of the set-ups and their monetary benefits.

\begin{tabular}{|c|c|c|c|c|}
\hline Cost $(\$)$ & Static FPC & \multicolumn{2}{|c|}{ Tracked FPC } & Concentrated FPC \\
\hline Collector cost & 756 & 756 & 756 & \\
\hline Pump cost & 50 & 50 & 50 & \\
\hline Tracking cost & 0 & 36 & 36 & \\
\hline Concentrator cost & 0 & 0 & 125 & \\
\hline Pumping energy cost & 108 & 108 & 108 & \\
\hline Tracking energy cost & 0 & 36 & 0 & \\
\hline \multirow[t]{2}{*}{ Total cost $(\$)$} & 914 & 950 & 1039 & \\
\hline & $\begin{array}{c}\text { Thermal energy } \\
(\mathrm{kWh} / \text { day })\end{array}$ & $\begin{array}{l}\text { Equivalent electrical } \\
\text { energy (kWh/day) }\end{array}$ & $\begin{array}{c}\text { Yearly electrical } \\
\text { energy (MWh/year) }\end{array}$ & $\begin{array}{c}\text { Yearly } \\
\text { saving (\$) }\end{array}$ \\
\hline Static & 39.2 & 11.76 & 3.5 & 304 \\
\hline Single axis tracking (vertical) & 41.7 & 12.51 & 3.7 & 322 \\
\hline Single axis tracking (horizontal) & 43.6 & 13.08 & 3.9 & 340 \\
\hline Double axis tracking & 45.1 & 13.51 & 4.1 & 357 \\
\hline Concentrator & 56.2 & 16.86 & 5.1 & 444 \\
\hline
\end{tabular}


The simple payback period is calculated by dividing the total cost of the system (initial investment as well as operating cost) by the economic benefit of the energy produced in the first year applying the values of energy harvested and electricity rates. The static case has the longest payback period of almost 3 years. Payback period reduced gradually with the improvement in thermal gain via different ways of tracking and/or concentration. In the optimized case, the payback period is reduced to almost 2 years.

\section{Conclusion}

This study examined the energy performance of SWHS in various building types under the hot climate of UAE, through TRNSYS simulation model. The parametric simulation determined the optimal collector parameters of tilt angle, azimuth angle and collector inlet water flow rate with respect to different seasons, building types and water demands. An optimal tilt angle of each month was identified to exploit the maximum potential of the system in Abu Dhabi, UAE which ranged from $50^{\circ}$ at maximum for January to $0^{\circ}$ for May. The optimum azimuth angle was found to be $0^{\circ}$ (south facing) rendering a drop of $22 \%$ and $30 \%$ in thermal yield when the collector faced exact East and West respectively. It was observed that the roof applied collectors (both flat and pitched) are more effective than wall mounted collectors. Eventually, the collector area required per building area was determined for each building type with the hospital requiring, in the best case, the highest ratio value. The solar collector tracking was then evaluated as a means of reducing the area allocated to install the collectors on top of a roof or on a facade. The needs for solar radiation concentration is determined for some building types to deliver the higher required temperatures. It was also evident that the number of required collectors decrease for each building as the axis of tracking increases. Finally, the system feasibility is calculated for the payback period and the optimized case will be able to return its cost in almost 2 years.

These results would provide building professionals with a quick assessment of the possibility to integrate the required area or number of SWHS collectors to meet the hot water demand in new or retrofitted buildings.

\section{Nomenclature}

$A_{c} \quad$ aperture area of the collector $\left(\mathrm{m}^{2}\right)$

$C_{H X} \quad$ heat-capacitance of coiled heat-exchanger $(\mathrm{kJ} /$ K)

$C_{p c} \quad$ specific heat of collector fluid $(\mathrm{kJ} /(\mathrm{kg} \mathrm{K}))$

$C_{\text {tank }}$ heat capacitance of storage tank $(\mathrm{kJ} / \mathrm{K})$

DHW domestic hot water

$f_{c} \quad$ collector-fin efficiency factor

$f_{r} \quad$ overall collector heat-removal efficiency factor

$I_{b} \quad$ incident-beam radiation per unit area $\left(\mathrm{kWh} / \mathrm{m}^{2}\right)$

$I_{d} \quad$ diffused radiation per unit area $\left(\mathrm{kWh} / \mathrm{m}^{2}\right)$
$I_{t} \quad$ global radiation on horizontal surface per unit area $\left(\mathrm{kWh} / \mathrm{m}^{2}\right)$

$I_{t i} \quad$ total incident-radiation on a flat surface per unit area $\left(\mathrm{kWh} / \mathrm{m}^{2}\right)$

$m_{c} \quad$ collector fluid mass-flow rate $(\mathrm{kg} / \mathrm{h})$

$n_{c} \quad$ number of collectors mounted in series

$n_{g} \quad$ number of glass covers

$Q_{c} \quad$ rate of heat gain collector array $(\mathrm{kW})$

$Q_{\text {in, HX }}$ rate of heat gains of coiled heat-exchanger $(\mathrm{kW})$

$Q_{\text {in, tank }}$ rate of heat gains of storage tank $(\mathrm{kW})$

$Q_{\text {out, HX }}$ rate of heat loss of coiled heat-exchanger $(\mathrm{kW})$

$Q_{\text {out, tank }}$ rate of heat loss from storage tank $(\mathrm{kW})$

$r_{g} \quad$ ground reflectance

SWHS solar water heating systems

SHC solar heating and cooling systems

$T_{a} \quad$ ambient temperature $\left({ }^{\circ} \mathrm{C}\right)$

$T_{\mathrm{av}} \quad$ collector-fluids average temperature $\left({ }^{\circ} \mathrm{C}\right)$

$T_{\text {hwa }}$ hot-water average temperature $\left({ }^{\circ} \mathrm{C}\right)$

$T_{\text {hw1 }} \quad$ hot-water initial temperature $\left({ }^{\circ} \mathrm{C}\right)$

$T_{\text {hw2 }} \quad$ hot-water final temperature $\left({ }^{\circ} \mathrm{C}\right)$

$T_{H X} \quad$ temperature of coiled heat-exchanger $\left({ }^{\circ} \mathrm{C}\right)$

$T_{i} \quad$ temperature of fluid entering the collector $\left({ }^{\circ} \mathrm{C}\right)$

$T_{p} \quad$ collector-plates temperature at stagnation $\left({ }^{\circ} \mathrm{C}\right)$

$T_{\text {tank }} \quad$ temperature of storage tank $\left({ }^{\circ} \mathrm{C}\right)$

$U_{b e} \quad$ heat loss coefficient of collector bottom surface $\left(\mathrm{kWh} / \mathrm{m}^{2} \mathrm{~K}\right)$

$U_{c} \quad$ overall heat loss-coefficient of collector $(\mathrm{kWh} /$ $\left.\mathrm{m}^{2} \mathrm{~K}\right)$

\section{Symbols}

$\alpha \quad$ absorptance of absorber plate

$\varepsilon_{g} \quad$ emissivity of glass covers

$\varepsilon_{p} \quad$ emissivity of absorber plate

$\sigma \quad$ Stefan-Boltzmann constant $\left(5.6697 \times 10^{-8} \mathrm{~W} /\left(\mathrm{m}^{2} \mathrm{~K}^{4}\right)\right)$

$\tau$ transmittance of absorber plate

$\Delta t$ simulation time-step (h)

$\varphi \quad$ collector latitude angle $\left({ }^{\circ}\right)$

$\beta$ collector azimuth angle $\left(^{\circ}\right)$

$\Phi$ collector tilt angle $\left(^{\circ}\right)$

The authors gratefully acknowledge financial support from the United Arab Emirates University through the Emirates Centre for Energy and Environment research funded project (31R054).

\section{References}

1. Dubai Electricity \& Water Authority (DEWA), Annual Statistics, https://www.dewa.gov.ae/en/about-dewa/ about-us/dewa-publications/annual-statistics

2. U.S. Environmental protection agency, draft inventory of U. S. greenhouse gas emissions and sinks:1990-2014 (U.S. environmental protection agency, Washington, 2016)

3. U.S. Energy information administration, issues in international energy consumption analysis: Canadian energy demand, (2015) 
4. R. Kempener, G. Simbolotti, G. Tosato, Solar Heating and Cooling for Residential Applications (International renewable energy agency, 2015)

5. M.D. Islam, I. Kubo, M. Ohadi, A.A. Alili, Measurement of solar energy radiation in Abu Dhabi, UAE, Appl. Energy 86, 511-515 (2009)

6. A. Hasan, H. Alnoman, Y. Rashid, Impact of integrated photovoltaic-phase change material system on building energy efficiency in hot climate, Energy Build. 130, 495-505 (2016)

7. A. Hasan, K.A. Al-Sallal, H. Alnoman, Y. Rashid, S. Abdelbaqi, Effect of Phase Change Materials (PCMs) Integrated into a Concrete Block on Heat Gain Prevention in a Hot Climate, Sustainability 8, 1009 (2016)

8. F.A. Ghaith, R. Abusitta, Energy analyses of an integrated solar powered heating and cooling systems in UAE, Energy Build. 70, 117-126 (2014)

9. A. Al-Alili, M.D. Islam, I. Kubo, Y. Hwang, R. Radermacher, Modeling of a solar powered absorption cycle for Abu Dhabi, Appl. Energy 93, 160-167 (2012)

10. F. Jafarkazemi, S.A. Saadabadi, Optimum tilt angle and orientation of solar surfaces in Abu Dhabi, UAE, Renew. Energy 56, 44-49 (2013)

11. A. Khalil, A. Alnajjar, Experimental and theoretical investigation of global and diffuse solar radiation in the United Arab Emirates, Renew. Energy 6, 537-543 (1995)

12. A transient system simulation program-program manual, University of Wisconsin-Madison, USA: Solar energy laboratory, TRNSYS 17 (2004)

13. International Building Code 2009, https://law.resource.org/ pub/us/code/ibr/icc.ibc.2009.html

14. ASHRAE HANDBOOK 2011 HVAC Applications SI Edition

15. The engineering toolbox (2016), http://www.engineeringtool box.com/design-hot-water-system-d_92.html

16. S.A. Klein, Calculation of flat-plate collector loss coefficients, Sol. Energy 17, 79-80 (1975)

17. Solar-energy laboratory, IIsibat version 3.0.0.26, TRNSYS 15.3., Solar-energy laboratory university of Wisconsin Madison

18. M.R. Islam, K. Sumathy, S.U. Khan, Solar water heating systems and their market trends, Renew. Sustain. Energy Rev. 17, 1-25 (2013)
19. I.R. Pillai, R. Banerjee, Impact of hot water usage pattern and location on economics of solar water heating systems, Water Energy Abstr. 14, (2004)

20. A. Lowenstein, C. C. Hiller, Disaggregating residential hot water use - Part II', ASHRAE Trans. 104, 1852-1863 (1998)

21. NAHB Research Center, Inc (2002), Performance comparison of residential hot water systems, Report prepared for National Renewable Energy Laboratory, Colorado

22. A. Gadgil, Economic, materials and performance constraints on the design of a solar DHW system for use in India, SESI J. 1, 31-36 (1987)

23. I.R. Pillai, R. Banerjee, Methodology for estimation of potential for solar water heating in a target area, Sol. Energy 81, 162-172 (2007)

24. K. L. Narkhede, Solar water heater as a demand side management option, M. Tech. Dissertation, Energy Systems Engineering, (Indian Institute of Technology, Bombay, India, 2001)

25. A. Shariah, M.A. Al-Akhras, I.A. Al-Omari, Optimizing the tilt angle of solar collectors, Renew. Energy 26, 587-598 (2002)

26. H. Moghadam, F.F. Tabrizi, A.Z. Sharak, Optimization of solar flat collector inclination, Desalination 265, 107-111 (2011)

27. M.D. Islam, A.A. Alili, I. Kubo, M. Ohadi, Measurement of solar-energy (direct beam radiation) in Abu Dhabi, UAE, Renew. Energy 35, 515-519 (2010)

28. M. Kacira, M. Simsek, Y. Babur, S. Demirkol, Determining optimum tilt angles and orientations of photovoltaic panels in Sanliurfa, Turkey, Renew. Energy 29, 1265-1275 (2004)

29. L. El Chaar, L.A. Lamont, Global solar radiation: multiple on-site assessments in Abu Dhabi, UAE, Renew. Energy 35, 1596-1601 (2010)

30. A. Hasan, H. Alnoman, A.H. Shah, Energy efficiency enhancement of photovoltaics by phase change materials through thermal energy recovery, Energies 9, 782 (2016)

31. Dubai Electricity \& Water Authority - tariff, https://www. dewa.gov.ae/en/customer/services/consumption-services/ tariff

32. Solar Balance-of-System: To Track or Not to Track, Part I, https://www.greentechmedia.com/articles/read/solar-bal ance-of-system-to-track-or-not-to-track-part-i

Cite this article as: K. Tabet Aoul, A. Hasan and H. Riaz: Solar water heating systems for different buildings under a hot climate; parametric optimization and economic analysis. Sust. Build. 3, 3 (2018). 